\title{
Investigating the Effect of Virtual Laboratory Simulation in Chemistry on Learning Achievement, Self-efficacy, and Learning Experience
}

\author{
https://doi.org/10.3991/ijet.v16i20.2356 \\ Chattavut Peechapol \\ Southeast Asia University, Bangkok, Thailand \\ chatesau.ac.th
}

\begin{abstract}
The purpose of this study was to investigate the effect of virtual laboratory simulation in chemistry on learning achievement, self-efficacy, and learning experience for first-year undergraduate students. This research was quasi-experiment with a two-group pretest-posttest design. The research used a purposive sampling of 95 first-year undergraduate students who enrolled in general chemistry subject. The participants were classified into two groups that consisted of the control group and the experimental group. Each group comprised members with low and high knowledge levels from the pre-test score. The control and experiment groups were required to learn chemistry topics in a traditional lecture for 3 hours. For the experimental group, students attended learning with the virtual lab simulation in chemistry for 1.5 hours. The results demonstrated that virtual lab simulation in chemistry had a positive effect on learning achievement, self-efficacy, and learning experience. The students who participated in the traditional lecture followed by virtual lab simulation had significantly higher knowledge and self-efficacy scores than learning through only a traditional lecture. Moreover, the effect of virtual lab simulation differed depending on levels of the students' initial knowledge and self-efficacy at pre-test, the group of low knowledge and self-efficacy levels gained a positive impact that was higher than the high-level group. The results of the learning experience found that virtual lab simulation encouraged students' motivation in learning and understanding the concept of chemistry via interactive 3D simulation. The results of this study indicated that virtual lab simulation could be an effective tool in supporting learning achievement and self-efficacy for learning chemistry. It was effective when a traditional lecture in chemistry was supplemented by virtual lab simulationbased learning.
\end{abstract}

Keywords — virtual laboratory simulation, self-efficacy, learning achievement, chemistry 


\section{$1 \quad$ Introduction}

Simulation-based learning refers to the use of simulation for learning purposes [1], it is a method of teaching and learning for supporting knowledge acquisition, development of skill and competencies and training dangerous tasks in a safe learning environment [2]. The simulations are used in various fields of education and training [3]: STEM (science, technology, engineering, and mathematics) education, medical education, and management. Chernikova et al. [3] demonstrated that simulation-based learning gave a chance for students to practices complex skills in higher education and eliminated limitations of learning in a real-life situation, the simulation affected positively learning and was an effective tool to facilitate the learning of complex skills.

Many students perceive that chemistry is difficult, complex, and abstract which required effort to understand. The reasons for chemistry that are difficult to learn, are the nature of the science itself makes it inaccessible and the problem of traditional teaching methods [4]. Kolil et al. [5] indicated that chemistry was perceived as a challenging subject resulting in reduced enrollment in chemistry course, the council of graduate schools exposed that enrollment of the undergraduate student in chemistry was slightly down over the past decade (2006-2016) with more than 1\%.

Self-efficacy is the powerful determinant affecting students' learning achievement and performance. It was presented by Bandura [6] that be defined as the belief in one's capability to organize and execute the actions required to produce particular results [7]. It is an important factor to students' learning that affects students' motivation, selfregulation, and learning achievement. There are many studies that indicate self-efficacy positively affects student's learning achievement $[8,9,10,11,12]$. For learning in chemistry, self-efficacy refers to one's beliefs about his or her ability to successfully perform specific tasks in chemistry [13]. The self-efficacy for learning chemistry can affect the effort that students spend on an activity, the student's persistence for learning, and the level of learning achievement. Students with high self-efficacy in learning chemistry are likely to try for learning and performing challenging tasks when compared with low chemistry self-efficacy [13].

However, few studies have investigated the effect of virtual lab simulation on selfefficacy. The purpose of this research was to study the effect of virtual lab simulation in chemistry on learning achievement, self-efficacy in the context of learning chemistry, and learning experience for first-year undergraduate students.

\subsection{Objective}

This study aimed to evaluate the effect of virtual laboratory simulation in chemistry on learning achievement, self-efficacy and learning experience of first-year undergraduate students. 


\section{Methodology}

\subsection{Method}

To study the effect of virtual lab simulation, the experiment was performed using a quasi-experiment with a two-group pretest-posttest design (Figure 1). The samples consisted of 95 first-year undergraduate students at Southeast Asia University, Thailand who participated in a general chemistry course. Participants were evaluated a prior knowledge and self-efficacy for chemistry learning (pre-test) with 30 minutes for classification of experiments groups. The participants were classified into two groups, the control group $(\mathrm{N}=45)$ and the experimental group $(\mathrm{N}=50)$. Each group comprised members with low (pre-test scores $=0-7$ ) and high (pre-test scores $=8$-15) knowledge from the pre-test. The control and experiment groups were required to learn chemistry subject for the topic of chemical bonds in a traditional lecture method for 3 hours. In addition, the experimental group attended learning with virtual lab simulation on the same topic and it took 1.5 hours. The virtual lab simulation as a tool for learning was developed by Labster [14]. Then, both groups were evaluated knowledge and self-efficacy levels (post-test). Moreover, the participants who learned via virtual lab simulation were inquired about a student's opinions via in-depth interview to obtain information about the learning experience.

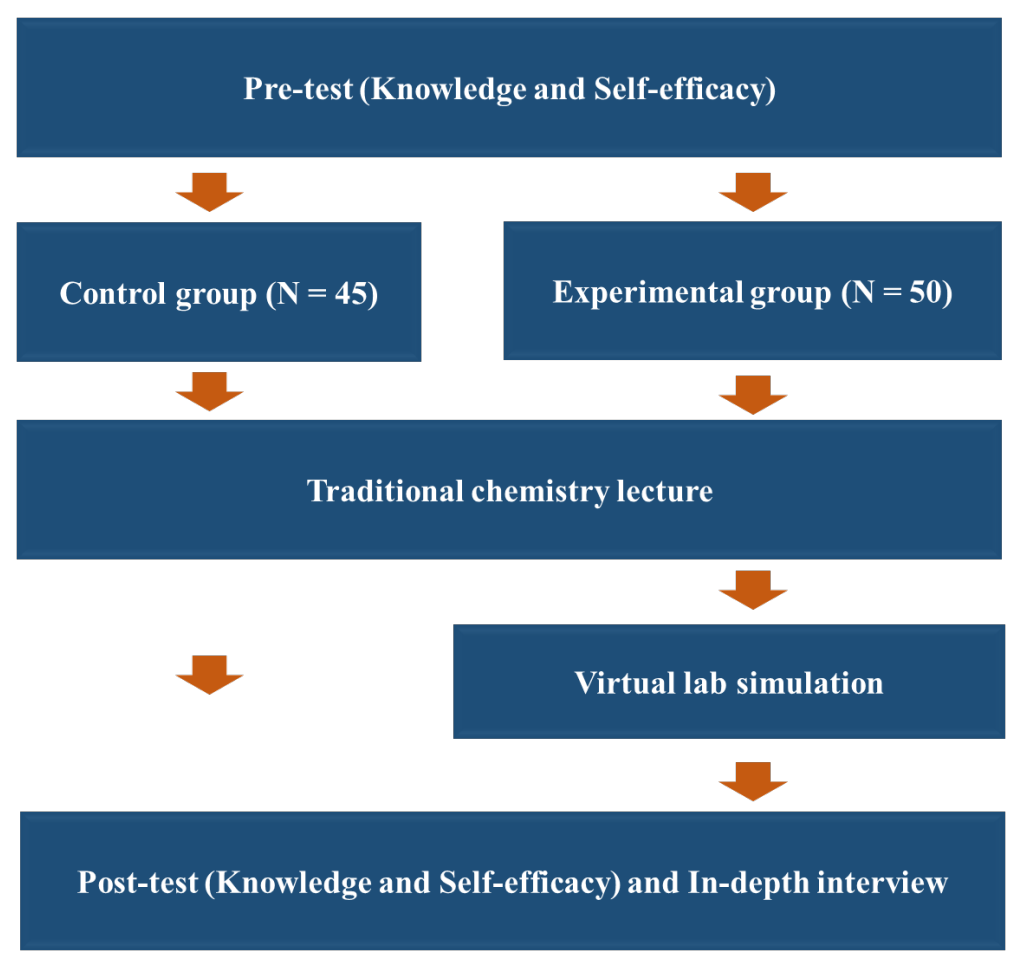

Fig. 1. Quasi-experiment with a two-group pre-test/post-test design 
Features of virtual lab simulation system comprise four elements to support student's learning in chemistry: 1) Interactive 3D simulation (Figure 2), it helps students understand the concepts of chemistry and prepare students for the laboratory experiment, the system allows students to practice laboratory experiment via virtual simulation before performing in the real lab; 2) Gamification and storytelling, the systems use gamification and storytelling approaches to motivate the students in learning; 3) Provide a quiz question with feedback, the student can learn the concept via quiz question with feedback; and 4) Provide the theoretical information.

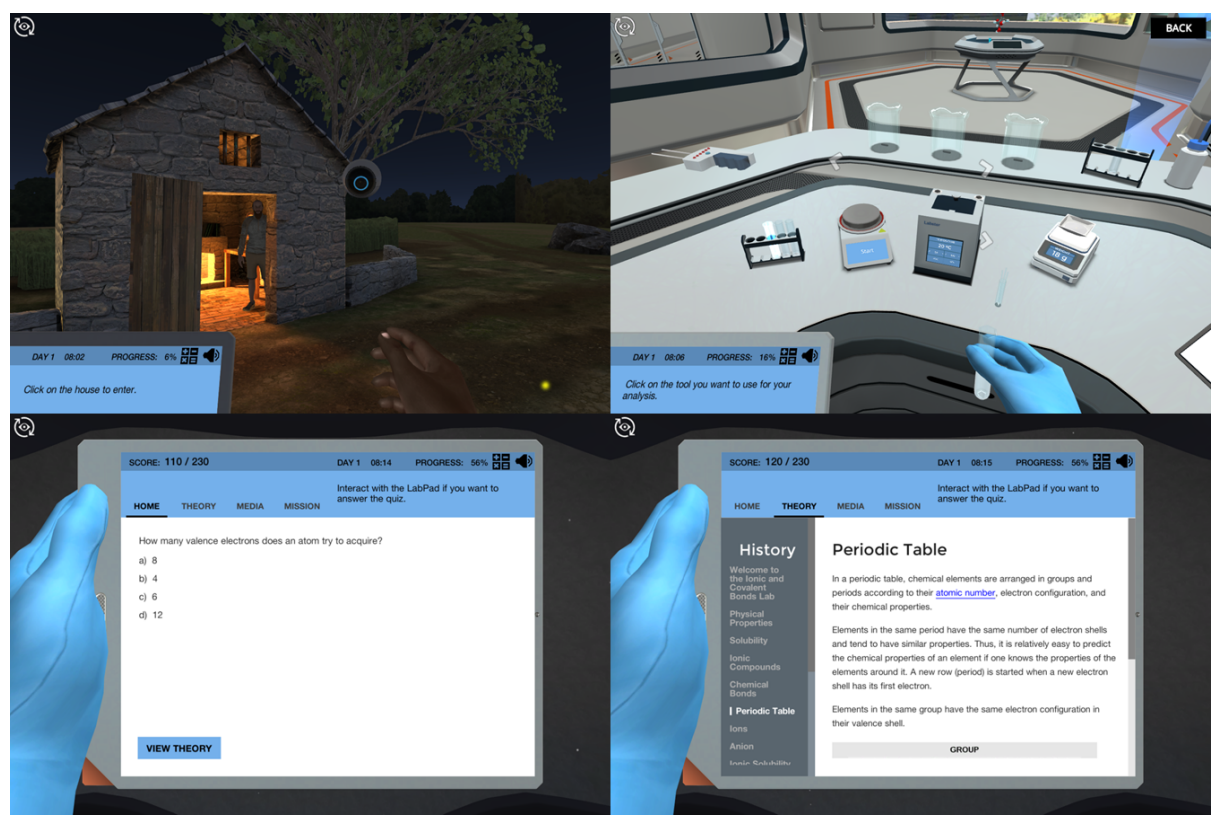

Fig. 2. Illustration of virtual laboratory simulation [14]

\subsection{Measurement}

For this study, the measurement of self-efficacy for chemistry learning was developed as an instrument to investigate the effect of virtual lab simulation in chemistry on student's self-efficacy. It measured student's beliefs their own ability to understand the concept of a specific topic in a chemistry course and to successfully perform relevant laboratory experiment. This study selected the topic of chemical bonds (ionic \& covalent bonds) because it is one of the fundamentals and abstract in chemistry. The six questionnaire items of student's self-efficacy measurement were developed with a 5point Likert scale $(1=$ cannot do, $3=$ can do with a moderate confidence and 5 can do with high confidence) that adapted from concepts of Smist [15] and Merchant et al. [16]. Example items are "I am confident that I can explain the concept of ionic and covalent bonds", I can do well on the exam question of chemical bonds and receive a 
Paper-Investigating the Effect of Virtual Laboratory Simulation in Chemistry on Learning...

score above $70 \%$. The questionnaire was high reliability with the Cronbach's Alpha 0.89 .

Knowledge level was assessed with multiple-choice 15 questions on chemical bonds (ionic and covalent bonds) to investigate the effect of virtual simulation in chemistry on student's learning achievement. Students received one point for every question answered correctly and zero for an incorrect answer.

\section{Results}

The results of this study consisted of: the effect of virtual lab simulation on learning achievement, self-efficacy, and learning experience. The comparison of pre-test and post-test scores were shown in Table 1.

Table 1. Comparison of average pre-test and post-test scores of knowledge and self-efficacy for experimental and control groups

\begin{tabular}{|c|c|c|c|c|c|}
\hline \multirow[t]{3}{*}{ Measure } & \multirow[t]{3}{*}{ Phase } & \multicolumn{3}{|c|}{ Experimental group } & Control group \\
\hline & & \multicolumn{3}{|c|}{$\mathbf{x},+\mathbf{S D}$} & \multirow{2}{*}{$\mathbf{x}, \pm$ SD } \\
\hline & & Low knowledge & High knowledge & Total & \\
\hline \multirow[t]{2}{*}{ Knowledge level } & Pre-test & $4.80 \pm 1.71$ & $8.93 \pm 0.88$ & $6.04 \pm 2.43$ & $6.27 \pm 1.79$ \\
\hline & Post-test & $10.97 \pm 1.36$ & $13.87 \pm 0.64$ & $11.84 \pm 1.79$ & $9.24 \pm 1.76$ \\
\hline \multirow[t]{2}{*}{ Self-efficacy } & Pre-test & $2.82 \pm 0.59$ & $3.63 \pm 0.40$ & $3.07 \pm 0.66$ & $3.11 \pm 0.54$ \\
\hline & Post-test & $3.84 \pm 0.48$ & $4.46 \pm 0.21$ & $4.03 \pm 0.50$ & $3.70 \pm 0.59$ \\
\hline
\end{tabular}

\subsection{Learning achievement}

The result of virtual lab simulation in chemistry on students' learning achievement was shown in Figure 3. The average pre-test and post-test scores of students' knowledge in the experimental group were 6.04 and 11.84, respectively. In the control group, average pre-test and post-test scores of students' knowledge were 6.27 and 9.24, respectively. The paired samples t-test analysis for the experimental group and control group showed that the average post-test scores of students' knowledge for both groups were significantly higher than the pre-test score $(\mathrm{P}<0.01)$. In addition, the average post-test score of students' knowledge for the experimental group was significantly higher than the control group which increased by $28.14 \%(\mathrm{P}<0.01)$. To study the effect of virtual lab simulation on learning achievement in different initial knowledge of students, the samples of the experimental group were classified into two groups based on pre-test scores: low $(\mathrm{N}=35$, pre-test scores $0-7)$ and high $(\mathrm{N}=15$, pre-test scores $8-15)$ knowledge level groups that were shown in Figure 4. The result demonstrated that the knowledge scores of each group increased significantly $(\mathrm{P}<0.01)$ as a result of the virtual lab simulation. The low knowledge level group was affected by the virtual lab simulation that was higher than the high knowledge level group, students' knowledge score of the low knowledge level group increased from 4.80 at pre-test to 10.97 at posttest, the increase was greater than the high knowledge level group by $24.90 \%$. 


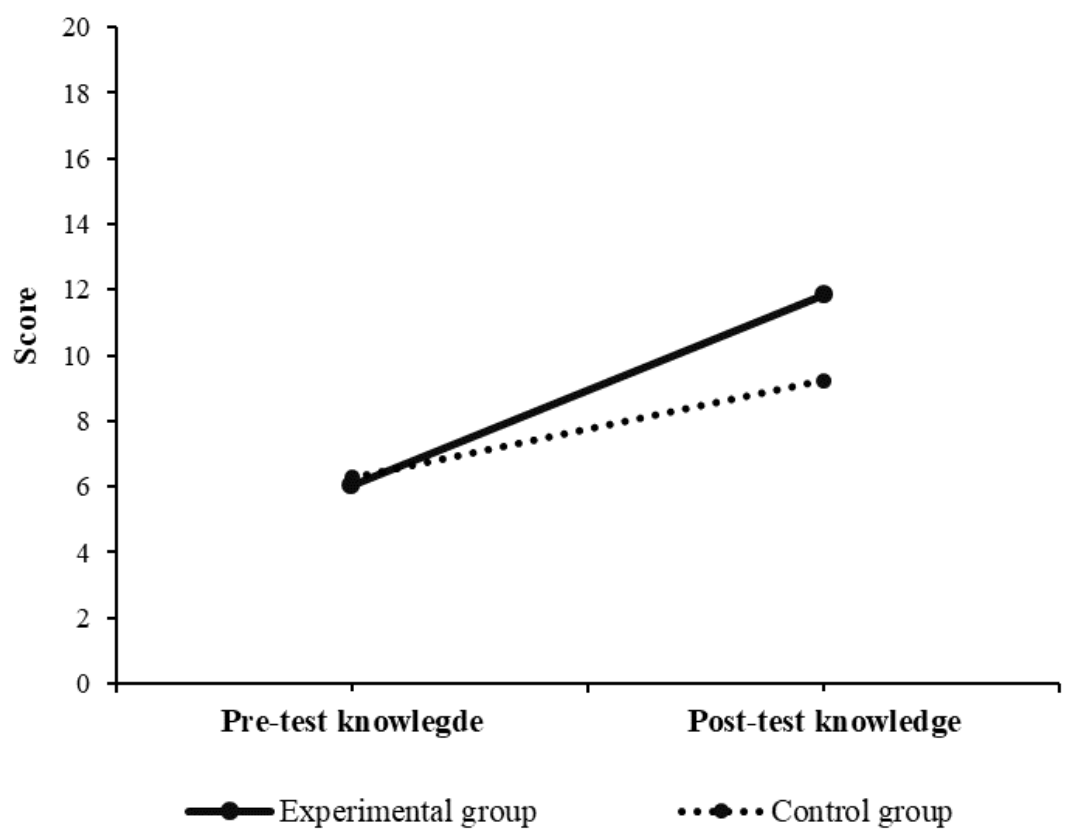

Fig. 3. Comparison of average pre/post-test knowledge scores of experimental and control groups.

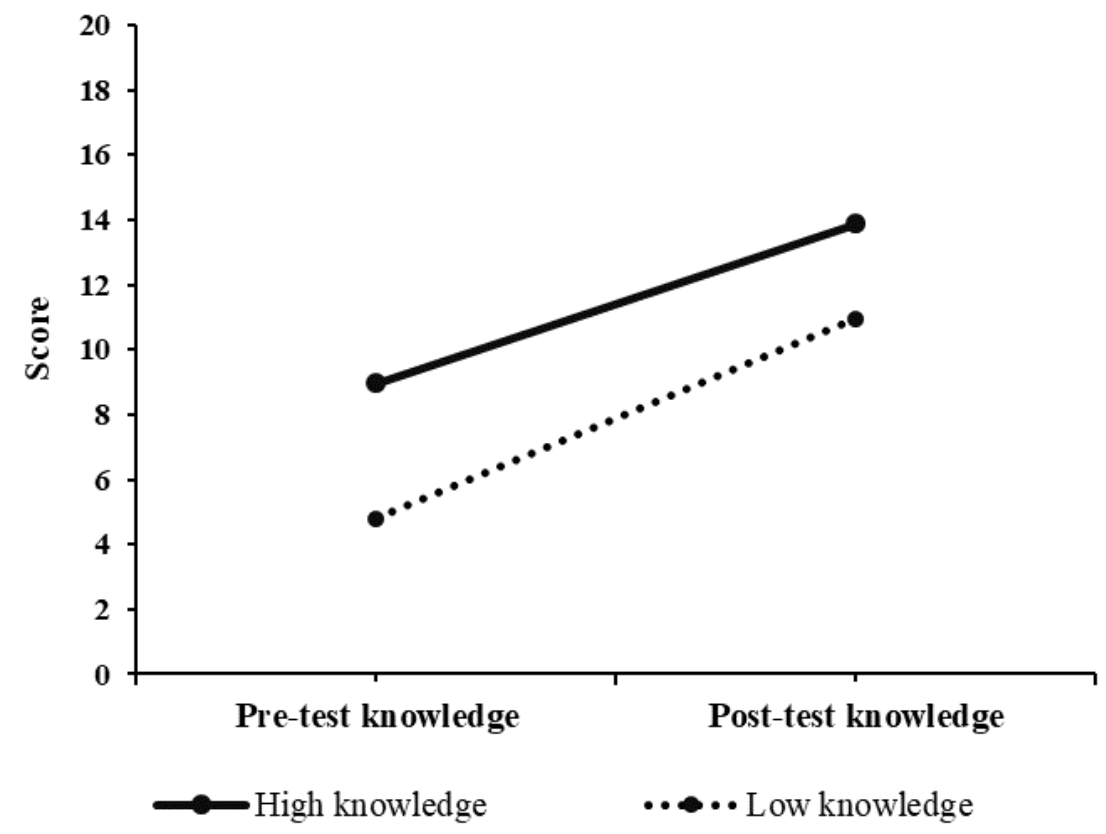

Fig. 4. Comparison of average pre/post-test knowledge scores of low and high knowledge level groups in experimental group. 


\subsection{Self-efficacy}

The results of self-efficacy were described in Figure 5-6. Paired samples t-test demonstrated that there was significantly a difference between average pre-test and post-test scores of self-efficacy for both experimental and control groups $(\mathrm{P}<0.01)$. For the experimental group, students' self-efficacy increased significantly from 3.07 at pretest to 4.03 at post-test, the increase was higher than the control group by $62.71 \%$. From independent t-test analysis, showed a significant difference in the post-test score of self-efficacy between the experimental and control groups $(\mathrm{P}<0.01)$. The post-test score of the experimental and control group were 4.03 and 3.70, respectively which post-test score of the experimental group was significantly higher than the control group. For the experiment group, average self-efficacy scores for both low and high knowledge level groups increased significantly $(\mathrm{P}<0.01)$ as shown in Fig 6. Paired samples t-test indicated that self-efficacy score for the low knowledge level group increased significantly from 2.82 in pre-test to 3.84 in post-test which increased by $36.17 \%$, while the high knowledge group increased significantly $22.86 \%$. These results demonstrated that the virtual lab simulation had positively a higher impact on self-efficacy for the low knowledge level group than the high knowledge level group.

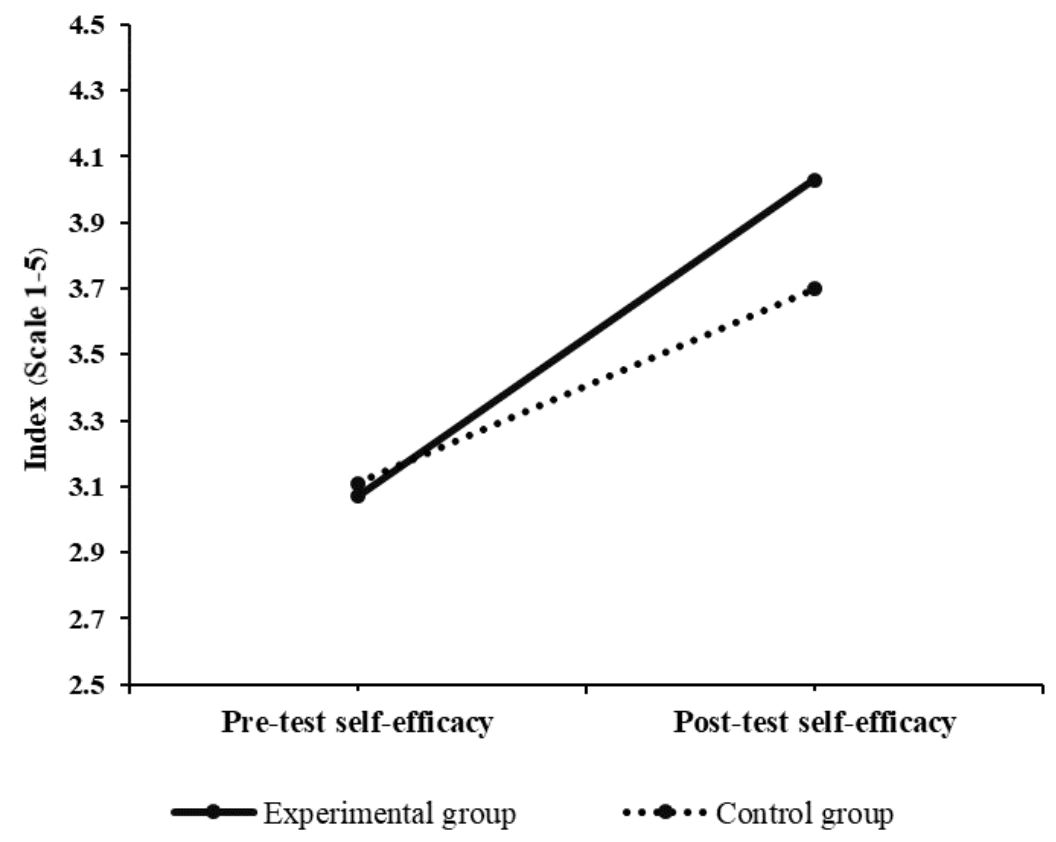

Fig. 5. Comparison of average pre/post-test self-efficacy scores of experimental and control groups. 


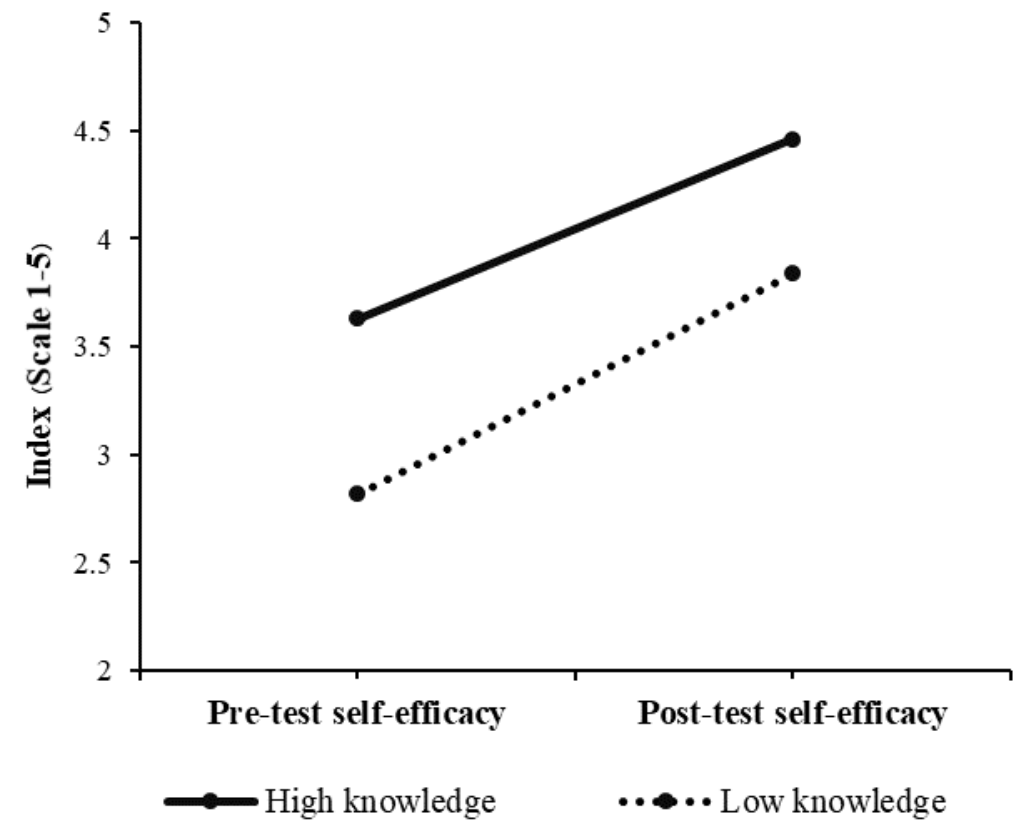

Fig. 6. Comparison of average pre/post-test self-efficacy scores of low and high knowledge level groups in experimental group.

\subsection{Learning experience}

To study the learning experience of students who participated in virtual lab simulation learning, in-depth interviews were used to gain students' opinions and feedbacks. Five students who participated in the virtual lab simulation were interviewed for 20-30 minutes per person. The results of the analysis of students' opinions via in-depth interviews were shown in Table 2, which indicated that the students who participated in virtual lab simulation-based learning had a positive learning experience as follows: 1) encouraging learning motivation, virtual lab simulation motivated students to learn. 2) easy to understand the concept through interactive $3 \mathrm{D}$ visualization and practice, the students indicated that virtual lab simulation helped them to visualize the chemical bond formation. 3) able to interact and perform the experiment, the students could perform laboratory experiment through simulation laboratory that was like a real lab. 4) able to learn with theory and quiz questions, the virtual lab simulation allowed students to learn via theory and quiz questions, students would be asked multiple questions when they learned and performed the experiment with virtual lab simulation. 5) receiving progress feedback, the system enabled students to perceive learning progress and feedbacks. 
Paper-Investigating the Effect of Virtual Laboratory Simulation in Chemistry on Learning...

Table 2. Students' opinions for virtual lab simulation through in-depth interview

\begin{tabular}{|l|l|}
\hline \multicolumn{1}{|c|}{ Positive Experience } & \multicolumn{1}{c|}{ Students' opinions } \\
\hline Encouraging learning motivation & $\begin{array}{l}\text { "I enjoyed learning with the simulation" } \\
\text { "I enjoyed learning with storytelling" } \\
\text { "I feel like playing a game" }\end{array}$ \\
\hline $\begin{array}{l}\text { Easy to understand the concept through } \\
\text { interactive 3D visualization and practice }\end{array}$ & $\begin{array}{l}\text { "I could not visualize chemical bond formation but virtual } \\
\text { simulation made me understand easily" } \\
\text { "I could visualize chemical bond formation" }\end{array}$ \\
\hline Able to interact and perform the experiment & $\begin{array}{l}\text { "I could interact with lab equipment like a real lab } \\
\text { "I could perform the experiment like a real lab" } \\
\text { "It was easy to perform the experiment" }\end{array}$ \\
\hline Able to learn with theory and quiz questions & "I could read the theory when met the questions" \\
\hline Receiving progress feedbacks & $\begin{array}{l}\text { "I was able to get progress when I perform the experiment" } \\
\text { "I received feedback when I answer a question" }\end{array}$ \\
\hline
\end{tabular}

\section{Discussion}

The study of the effect of virtual lab simulation in chemistry on learning achievement, self-efficacy, and learning experience. The findings of this study demonstrated that the virtual simulation-based learning environment had a positive effect on learning achievement, self-efficacy, and learning experience. Independent samples t-test showed the students who participated in the traditional lecture followed by virtual lab simulation had higher scores of knowledge and self-efficacy than students who learned with only the traditional lecture. These results were consistent with Makransky et al. [17] who found that simulation-based virtual learning environment increased students' knowledge, intrinsic motivation, and self-efficacy in medical education. In addition, Makransky et al. [18] demonstrated that virtual simulation increased the knowledge of microbiology, intrinsic motivation and self-efficacy in the fields of microbiology. Elangovan and lsmail [19] indicated that 3D computer simulation enhanced significantly learning achievement and memory retention for biology when compared with a traditional lecture. Additionally, the research of Merchant et al. [16], who studied the effect of 3D virtual reality environment on the learning of valence shell electron pair repulsion (VSEPR) theory, the result showed that $3 \mathrm{D}$ virtual reality environment had positively an impact on the score of test. The effect of virtual lab simulation in chemistry differed depending on the students' initial knowledge and self-efficacy (pre-test), the groups of low knowledge and self-efficacy level gained positively more impact than high knowledge and self-efficacy groups. It agreed with Markransky et al. [17] indicated that the strength of the effect of simulation-based learning depended on student's initial knowledge, the low initial knowledge group gained a positive impact which was higher than the high initial knowledge group. The finding of learning experience found that students who participated in virtual simulation-based learning had a positive experience for learning chemistry through the virtual lab simulation as follows: encouraging learning motivation, easy to understand the concept through visualization and practice, able to interact and perform the experiment, able to learn with theory and quiz questions, and receiving progress feedbacks. The results provided evidence that virtual lab 
simulation in chemistry enables students to: 1) visualize the concept of chemistry 2) motivate them to learn, 3) perform laboratory experiment like a real lab environment. It demonstrated virtual simulation-based learning resulted in enhancing student's knowledge and self-efficacy. Moreover, it also gave the opportunity to interact with lab equipment and perform laboratory experiment as well as a repeating experiment which enables students to learn the concepts of chemistry via practice and visualization. The increase of self-efficacy might be due to the features of virtual lab simulation comprised four elements to support student's learning in chemistry: 1) Interactive 3D simulation, it enabled students to easily understand the theoretical information and concepts in chemistry and preparing students for the laboratory experiment, the system enabled students to perform laboratory experiment via virtual simulation before performing in the real lab; 2) Gamification and storytelling, the systems used gamification and storytelling approaches to motivate the students; 3) Provided a quiz questions with feedbacks, the student could learning the concept via quiz questions with feedbacks that there were reports that feedback is one of the most important factors for supporting selfefficacy [20]; and 4) Provided the theoretical information. These features might be the cause of enhancing the student's knowledge and self-efficacy in learning chemistry. It was consistent with the sources of self-efficacy described in Bandura [7] that was performance accomplishment, refer to students' actual experiences of success in task performance [13], the best way to improve students' performance was practice [21]. The virtual lab simulation allowed students to understand the concepts of chemistry through interactive 3D visualization and to perform successfully a task via the virtual lab experiment. These results indicated that virtual lab simulation could be an effective tool for enhancing learning achievement and self-efficacy for learning chemistry via learning and practice in the virtual lab. It was effective when a traditional lecture in chemistry was supplemented by virtual laboratory simulation.

\section{Conclusion}

This research presented the effect of virtual lab simulation in chemistry on the learning achievement, self-efficacy and learning experience of first-year undergraduate students. The results demonstrated that the virtual lab simulation had a positive impact on student's learning achievement and self-efficacy. The student who learned chemistry through a traditional lecture supplementing by virtual lab simulation had higher scores of knowledge and self-efficacy than learning with only a traditional lecture. the effect of virtual lab simulation depended on the students' initial knowledge and self-efficacy levels at the pre-test score, the group with low levels of knowledge and self-efficacy gained the positive effect that was higher than high-level groups. Moreover, the virtual lab simulation-based learning contributed to students' motivation in learning and helped them understand complex concepts in chemistry as well as preparing to perform in a real laboratory experiment that could connecting theory with practice. These results showed evidence that virtual lab simulation has the potential to be an effective tool for learning chemistry. 
Paper-Investigating the Effect of Virtual Laboratory Simulation in Chemistry on Learning...

\section{References}

[1] Frasson, C., \& Blanchard, E.G. (2012). Simulation-Based Learning. In: Seel N.M. (eds) Encyclopedia of the Sciences of Learning. Springer, Boston, MA. https://doi.org/10.1007/978-1-44191428-6 129

[2] Lohmann, R. (2020). Effects of simulation-based learning and one way to analyze them. Journal of Political Science Education, 16(4): 479-495. https://doi.org/10.1080/15512169. 2019.1599291

[3] Chernikova, O., Heitzmann, N., Stadler, M., Holzberger, D., Seidel, T., \& Fischer, F. (2020). Simulation-based learning in higher education: A meta-analysis. Review of Educational Research, 90(4): 499-541. https://doi.org/10.3102/0034654320933544

[4] Cardellini, L. (2012). Chemistry: why the subject is difficult? Educación química, 23: 305310. https://doi.org/10.1016/s0187-893x(17)30158-1

[5] Kolil, V. K., Muthupalani, S., \& Achuthan, K. (2020). Virtual experimental platforms in chemistry laboratory education and its impact on experimental self-efficacy. International Journal of Educational Technology in Higher Education, 17(1): 1-22. https://doi.org 110.1186/s41239-020-00204-3

[6] Bandura, A. (1986). Social foundations of thought and action: A social cognitive theory. Englewood Cliffs, NJ: Prentice-Hall. https://doi.org/10.5465/amr.1987.4306538

[7] Bandura, A. (1997). Self-efficacy: The exercise of control. New York: W.H. Freeman.

[8] Adeyemo, D. A. (2007). Moderating influence of emotional intelligence on the link between academic self-efficacy and achievement of university students. Psychology and developing societies, 19(2): 199-213. https://doi.org/10.1177/097133360701900204

[9] Balkis, M. (2011). Academic efficacy as a mediator and moderator variable in the relationship between academic procrastination and academic achievement. Eurasian Journal of Educational Research, 45: 1-16.

[10] Collins, J. (1982). Self-efficacy and ability in achievement behavior Paper presented at the Annual Meeting of the American Educational Research Association. New York.

[11] Van Dinther, M., Dochy, F., \& Segers, M. (2011). Factors affecting students' self-efficacy in higher education. Educational research review, 6(2): 95-108. https://doi.org/10.1016/j.edurev.2010. $\underline{10.003}$

[12] Chen, Y. (2020). Correlation between Self-Efficacy and English Performance. International Journal of Emerging Technologies in Learning (iJET), 15(8): 223-234. https://doi. org/10.3991/ijet.v15i08.13697

[13] Cheung, D. (2015). Secondary school students' chemistry self-efficacy: Its importance, measurement, and sources. In Affective dimensions in chemistry education (pp. 195-215). Springer, Berlin, Heidelberg. https://doi.org/10.1007/978-3-662-45085-7 10

[14] Labster (2021). General Chemistry. Retrieved from: https://www.labster.com

[15] Smist, J. M. (1993). General chemistry and self-efficacy. Paper presented at the national meeting of the American Chemical Society, Chicago, IL (ERIC ED368558).

[16] Merchant, Z., Goetz, E. T., Keeney-Kennicutt, W., Kwok, O. M., Cifuentes, L., \& Davis, T. J. (2012). The learner characteristics, features of desktop 3D virtual reality environments, and college chemistry instruction: A structural equation modeling analysis. Computers \& Education, 59(2): 551-568. https://doi.org/10.1016/j.compedu.2012.02.004

[17] Makransky, G., Bonde, M. T., Wulff, J. S., Wandall, J., Hood, M., Creed, P. A., \& Nørremølle, A. (2016). Simulation based virtual learning environment in medical genetics counseling: an example of bridging the gap between theory and practice in medical education. BMC medical education, 16(1): 1-9. https://doi.org/10.1186/s12909-016-0620-6 
Paper-Investigating the Effect of Virtual Laboratory Simulation in Chemistry on Learning...

Makransky, G., Thisgaard, M. W., \& Gadegaard, H. (2016). Virtual simulations as preparation for lab exercises: Assessing learning of key laboratory skills in microbiology and improvement of essential non-cognitive skills. PloS one, 11(6), e0155895. https://doi.org/10.1371 /journal.pone.0155895

[19] Elangovan, T., \& Ismail, Z. (2014). The effects of 3D computer simulation on biology students' achievement and memory retention. In Asia-Pacific Forum on Science Learning \& Teaching, 15(2): 1-25.

[20] Peechapol, C., Na-Songkhla, J., Sujiva, S., \& Luangsodsai, A. (2018). An Exploration of Factors Influencing Self-Efficacy in Online Learning: A Systematic Review. International Journal of Emerging Technologies in Learning (iJET), 13(9): 64-86. https://doi.org/ 10.3991/ijet.v13i09.8351

[21] Hussain, A., Mkpojiogu, E. O., \& Ezekwudo, C. C. (2021). Improving the Academic SelfEfficacy of Students Using Mobile Educational Apps in Virtual Learning: A Review. International Journal of Interactive Mobile Technologies, 15(6): 149-160. https://doi.org/10. $\underline{\text { 3991/ijim.v15i06.20627 }}$

\section{Author}

Chattavut Peechapol is a Ph.D. in Technopreneurship and Innovation Management. He is currently a lecturer at Southeast Asia University, Bangkok, Thailand. His main research interests are in educational innovation and information technology management.

Article submitted 2021-04-26. Resubmitted 2021-06-05. Final acceptance 2021-06-08. Final version published as submitted by the author. 